\title{
Assessment of Genetic Diversity in Parental Lines of Pearl Millet [Pennisetum glaucum (L). R. Br] for Yield and Yield Related Traits
}

\author{
R. Rasitha ${ }^{1 *}$, K. Iyanar ${ }^{1}$, R. Ravikesavan ${ }^{1}$ and N. Senthil ${ }^{2}$ \\ ${ }^{1}$ Department of Millet, Centre for Plant Breeding and Genetics, ${ }^{2}$ Department of Plant \\ Molecular Biology and Bioinformatics, Centre for Plant Biology and Bioinformatics, Tamil \\ Nadu Agricultural University, Coimbatore - 641003 \\ *Corresponding author
}

\begin{tabular}{|c|}
\hline Keywords \\
\hline $\begin{array}{l}\text { Pearl millet, } \mathrm{D}^{2} \\
\text { diversity, PCA, } \\
\text { parental lines, } \\
\text { hybridization } \\
\text { programme }\end{array}$ \\
\hline Article Info \\
\hline $\begin{array}{l}\text { Accepted: } \\
12 \text { November } 2020 \\
\text { Available Online: } \\
10 \text { December } 2020\end{array}$ \\
\hline
\end{tabular}

\section{A B S T R A C T}

The effective selection of parents and further utilization for hybridization programme depends on the knowledge about genetic makeup of experimental material. In order to assess the genetic diversity among the seed parents and restorers, a study was conducted to identify the potential parents and variables for further selection. A total of 59 parental lines which includes maintainer and restorer lines of pearl millet were characterized based on quantitative characters. Considerable variation was observed in all the studied characters. Genetic divergence analysis was carried out based on multivariate analysis using Mahalanobis's $\mathrm{D}^{2}$ statistics and PCA. In $\mathrm{D}^{2}$ analysis, the experimental materials were grouped into five major clusters. Cluster I having the highest number of lines followed by cluster II due to common ancestry of parental lines. The highest inter cluster distance was observed between cluster I and V followed by cluster III and IV. Based on cluster mean performance the line belonging to cluster $\mathrm{V}$ recorded high mean performance for yield attributing quantitative characters like spike length, spike girth, leaf blade length, leaf blade width, 1000 seed weight and dry fodder yield and Cluster IV showed the highest value for number of productive tillers/plant and plant height and days to 50 percent flowering. Selection of lines belongs to this clusters will provide high yielding hybrids in breeding programme. The principal component analysis was used for data reduction method and it generate different principal components. The first three PC's explained $63.8 \%$ of total variability of among the parental lines. Based on factor loading of three PC's explained that the traits viz., days to 50 percent flowering, leaf blade width and spike girth act as a good selection indices which shows positive loading towards genetic diversity. The parental lines viz., PT 6697, PT 6059, PT 6347, PT 6069, CBMS 185B/3-2, CBMS 134B/5-3, CBMS 135B/1-3, CBMS 173B/4-5 shows diverse in both $\mathrm{D}^{2}$ and PCA analysis and It revealed that utilization of this parental lines for hybridization programme will yield positive results.

\section{Introduction}

Pearl millet is an important stable millet food crop for arid and semiarid regions of Africa and Indian countries. Pearl millet is well adapted to drought prone area, low fertility and high temperature where other cereal crop fails to grow. But this crop gives low grain 
yield owing to cultivation in unfavorable environment conditions like poor rainfall area, eroded soils and low input conditions. Development of high yielding varieties through hybridization programme is an effective approach for increasing the production of Pearl millet. Pearl millet exhibits tremendous amount of diversity at both phenotypic and genotypic level because its wide adaptation to different environmental conditions (Ramya et al., 2017). Diversity studies give the precise information about nature and degree of genetic diversity in plants which help the plant breeders to select the parents for hybridization programme. As the cross between more divergent parents will give more heterosis than the close related parents (Birchler et al., 2010).

The estimation of genetic distance existing between parents is essential for parent selection. Higher genetic distance between parents will give high heterosis (Singh et al., 2017). Genetic distance is measured by different multivariate analysis. Among the different multivariate analysis, Mahalanobis's generalized distance estimated by $\mathrm{D}^{2}$ statistics (Rao, 1952) serves as potential and unique tools for phenotypic diversity evaluation, identifying genetically distant clusters of genotypes and selecting important traits contributing to the total variation in the germplasm. Principal component analysis and clustering are the major approach for genetic distance analysis in cereals and millet crops like rice, finger millet and pearl millet. In PCA, the number of variables is reduced into linear function. Therefore, the present investigation carried out both $\mathrm{D}^{2}$ analysis and PCA analysis for selecting the genotypes for trait specific purpose (Kumari et al., 2016)

\section{Materials and Methods}

The present study was carried out with parental lines of pearl millet which include 42 maintainer lines and 17 restorer lines. The experimental material was raised in CRBD (Complete Randomized Block Design) with two replication during Kharif season 2018 in Department of Millet, TNAU Coimbatore. Each entry was raised in two rows with spacing of $45 \times 15 \mathrm{~cm}$. Recommended agronomic package and practices were followed during experimental period.

Data was recorded on five randomly selected plants from each replication of each lines for eleven quantitative characters viz., Days to 50 percent flowering, Leaf sheath length $(\mathrm{cm})$, Leaf blade length $(\mathrm{cm})$, Leaf blade width $(\mathrm{cm})$, Spike length $(\mathrm{cm})$, Spike girth, Number of productive tillers/plants, Plant height $(\mathrm{cm})$, 1000 seed weight $(\mathrm{g})$, Single plant yield(g) and Dry fodder yield $(\mathrm{g})$. The data were subjected statistical analysis using software WINDOSTAT ver 7.1. $\mathrm{D}^{2}$ analysis by Tocher method and PCA analysis were carried out in in NTSYSpc ver. 2.21t for the experimental material. The result and salient findings are presented below

\section{Results and Discussion}

Analysis of variance revealed that significant difference existing between experimental materials for all the studied characters and indicated that significant amount of variation among the genotypes (Table 1). Mehalanobis developed the concept of diversity in 1936, but Rao suggested the application of this technique for the assessment of genetic diversity in plant breeding material.

The Mehalanobis generalized distance measured by $\mathrm{D}^{2}$ statistic has been used for grouping genotypes. The success of obtaining highly heterotic hybrids and creating greater variability for efficient selection of useful recombinants in breeding programmes depend on the degree of divergence between the parents chosen. 
Table.1 Analysis of variance for eleven quantitative characters in 59 lines of pearl millet

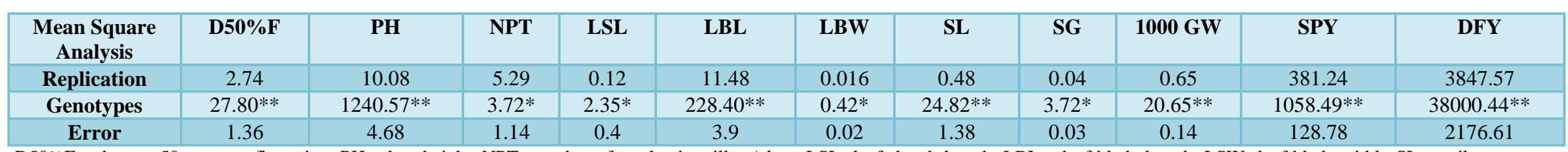

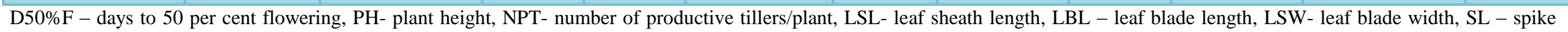
length, SG - spike girth, 1000 GW - 1000 grain weight, SPY- single plant yield, DFY- dry fodder yield

Table.2 Grouping of pearl millet lines into different clusters by Tocher's method

\begin{tabular}{|c|c|c|c|}
\hline S.No & Cluster No & $\begin{array}{l}\text { Number of } \\
\text { genotypes }\end{array}$ & Genotypes \\
\hline \multirow[t]{2}{*}{1} & I & 40 & $\begin{array}{l}\text { CBMS 172B/2-4,CBMS 173B/2-7,CBMS 167B/5-2,CBMS 167B/1-1,CBMS 5B/1-1,CBMS 173B/1-6,CBMS 173B/4-5,CBMS } \\
\text { 179B/4-1,CBMS 179B/1-1,CBMS 174B/1-1,CBMS 173B/1-1,CBMS 167B/4-4,CBMS 173B/3-3,CBMS 173B/2-5,CBMS } \\
\text { 156B/2-1,CBMS 165B/3-4,CBMS 158B/4-1,CBMS 167B/5-1,CBMS 47B/5-1,CBMS 174B/2-6,CBMS 174B/1-2,CBMS } \\
\text { 165B/4-3,CBMS 173B/1-5,CBMS 173B/2-1,CBMS 47B/1-1,CBMS 178B/1-6,CBMS 179B/4-4,CBMS 179B/4-6,CBMS } \\
\text { 179B/3-6,CBMS 178B/8-5,CBMS 135B/1-2,CBMS 178B/9-5,CBMS 184B/6-3,CBMS 108B/1-1,CBMS 174B/1-5,CBMS } \\
\text { 178B/1-3,, CBMS 135B/1-6 }\end{array}$ \\
\hline & & & PT 6674,PT 6675, PT 6059 \\
\hline 2 & II & 16 & $\begin{array}{l}\text { PT 6684,PT 6693,PT 6029, PT 6686, PT 6694, PT 6067, PT 6676, PT 6347, PT 6024,CBMS 134B/5-3, PT 6677,PT } \\
\text { 6715,CBMS 108B/3-6, CBMS 135B/1-3 }\end{array}$ \\
\hline 3 & III & 1 & CBMS 108B/1-2 \\
\hline 4 & IV & 1 & CBMS 185B/ 3-2 \\
\hline 5 & V & 1 & PT 6697 \\
\hline
\end{tabular}

Note: Bolded parental lines shows diverse nature in PCA scatter plot also

Table.3 Average inter and intra cluster distance for eleven quantitative characters

\begin{tabular}{|c|c|c|c|c|c|c|}
\hline Clusters & I & II & III & IV & V \\
\hline I & $\mathbf{1 6 . 1 2}$ & 31.23 & 24.27 & 38.69 & 52.18 \\
\hline II & & $\mathbf{2 0 . 0 7}$ & 27.67 & 28.30 & 39.40 \\
\hline III & & & $\mathbf{0 . 0 0}$ & 39.76 & 52.08 \\
\hline IV & & & & $\mathbf{0 . 0 0}$ & 45.55 \\
\hline V & & & & & $\mathbf{0 . 0 0}$ \\
\hline
\end{tabular}


Table.4 Cluster mean value for eleven characters of parental lines of pearl millet

\begin{tabular}{|c|c|c|c|c|c|c|c|c|c|c|c|}
\hline Clusters & D $50 \% \mathrm{~F}$ & PH & NPT & $1000 \mathrm{SW}$ & SPY & DFY & LSL & LBL & LBW & SL & SG \\
\hline I & 45.25 & 103.84 & 6.63 & 9.51 & 92.05 & 330.39 & 10.34 & 36.71 & 3.61 & 18.08 & 5.81 \\
\hline II & 46.63 & 148.42 & 6.06 & 14.59 & 110.06 & 363.17 & 11.97 & 55.32 & 3.56 & 23.37 & 7.10 \\
\hline III & 47.50 & 114.20 & 6.50 & 17.15 & 125.55 & 178.50 & 11.00 & 35.10 & 3.25 & 18.92 & 6.00 \\
\hline IV & 43.00 & 174.10 & 7.00 & 11.15 & 121.55 & 190.00 & 9.85 & 26.15 & 3.55 & 20.19 & 7.00 \\
\hline $\mathbf{V}$ & $\mathbf{5 7 . 5 0}$ & 153.50 & 6.00 & 15.30 & 81.25 & 530.00 & 11.85 & 67.65 & 5.05 & 30.47 & 12.72 \\
\hline$\%$ contribution & 2.75 & 0.00 & 3.74 & 3.21 & 0.23 & 13.85 & 0.06 & 49.74 & 20.75 & 0.76 & 4.91 \\
\hline
\end{tabular}

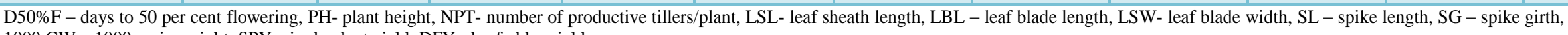
$1000 \mathrm{GW}-1000$ grain weight, SPY- single plant yield, DFY- dry fodder yield

Table.5 Eigen value and percentage of total variance of various principal components

\begin{tabular}{|l|c|c|c|}
\hline Component & Eigen values & Variance explained (\%) & Cumulative (\%) \\
\hline PC1 & $\mathbf{4 . 7 5 9 5}$ & $\mathbf{3 9 . 6 6}$ & $\mathbf{3 9 . 6 6}$ \\
\hline PC2 & $\mathbf{1 . 5 5 1 8}$ & $\mathbf{1 2 . 9 3}$ & $\mathbf{5 2 . 5 9}$ \\
\hline PC3 & $\mathbf{1 . 2 7 5 0}$ & $\mathbf{1 0 . 6 2}$ & $\mathbf{6 3 . 2 2}$ \\
\hline PC4 & 0.9096 & 7.58 & 70.80 \\
\hline PC5 & 0.8415 & 7.01 & 77.81 \\
\hline PC6 & 0.6787 & 5.66 & 83.47 \\
\hline PC7 & 0.5467 & 4.56 & 88.02 \\
\hline PC8 & 0.4641 & 3.87 & 91.89 \\
\hline PC9 & 0.3856 & 3.21 & 95.10 \\
\hline PC10 & 0.2717 & 2.26 & 97.37 \\
\hline PC11 & 0.1915 & 1.06 & 98.90 \\
\hline PC12 & 0.1243 & 1.04 & 100 \\
\hline
\end{tabular}

Table.6 Factor loading of eleven characters with respect to different principle components

\begin{tabular}{|c|c|c|c|c|c|c|c|c|c|c|c|c|}
\hline Characters & D50\%F & PH & NPT & LSL & LBL & LBW & SL & SG & 1000 GW & SPY & DFY & D50\%F \\
\hline PC 1 & 0.214 & 0.3675 & 0.3985 & 0.1004 & 0.2794 & 0.3747 & 0.3112 & -0.1466 & 0.3508 & 0.3947 & 0.1662 & 0.0832 \\
\hline PC 2 & 0.2735 & -0.041 & 0.0268 & 0.3413 & -0.2818 & 0.021 & 0.2873 & -0.5294 & -0.2326 & -0.0158 & -0.5531 & -0.0579 \\
\hline PC 3 & 0.1636 & -0.0597 & -0.1016 & 0.5424 & -0.0711 & -0.1348 & 0.1405 & 0.2539 & 0.2175 & -0.0682 & 0.2562 & -0.6634 \\
\hline
\end{tabular}

$\mathrm{D} 50 \% \mathrm{~F}$ - days to 50 per cent flowering, PH- plant height, NPT- number of productive tillers/plant, LSL- leaf sheath length, LBL - leaf blade length, LSW- leaf blade width, SL - spike length, SG spike girth, $1000 \mathrm{GW}$ - 1000 grain weight, SPY- single plant yield, DFY- dry fodder yield 
Fig.1 Clustering of parental lines by Tocher"s method

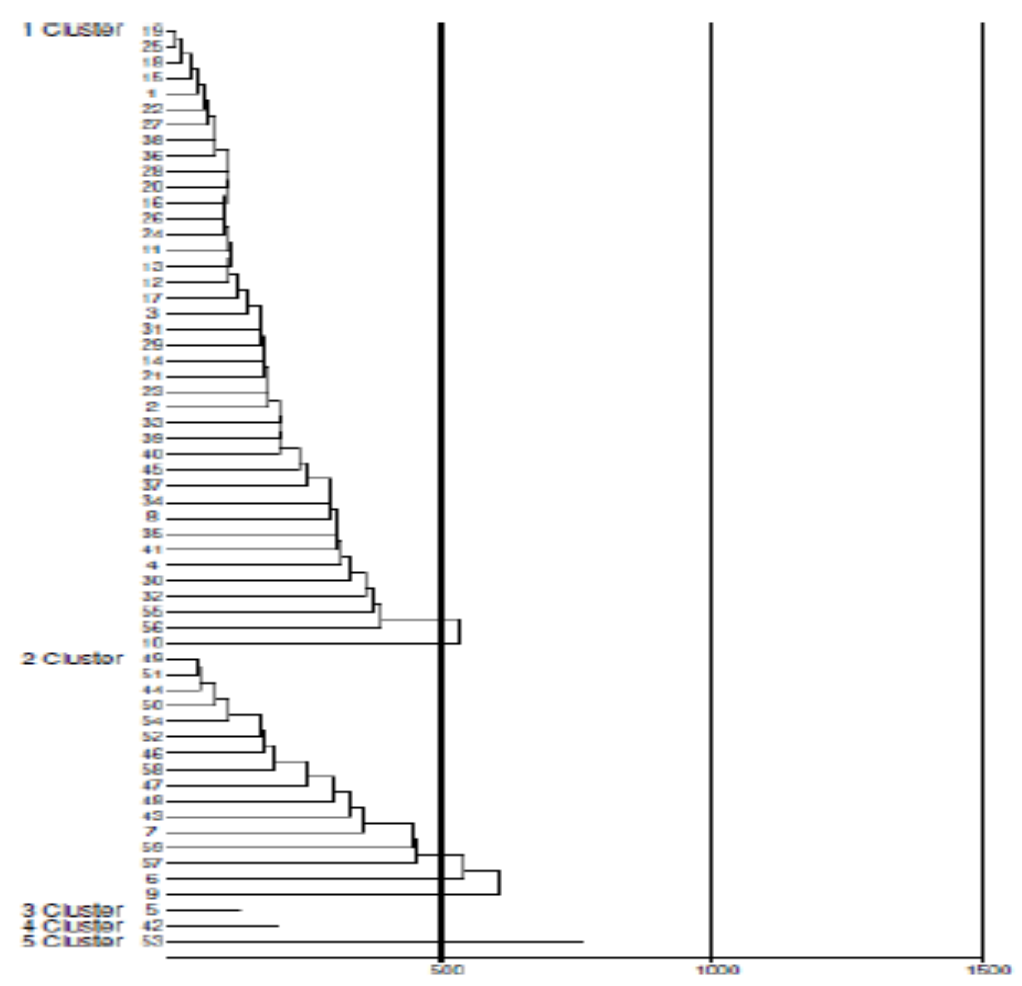

Fig.2 PCA scatter plot showing grouping of parental lines in pearl millet

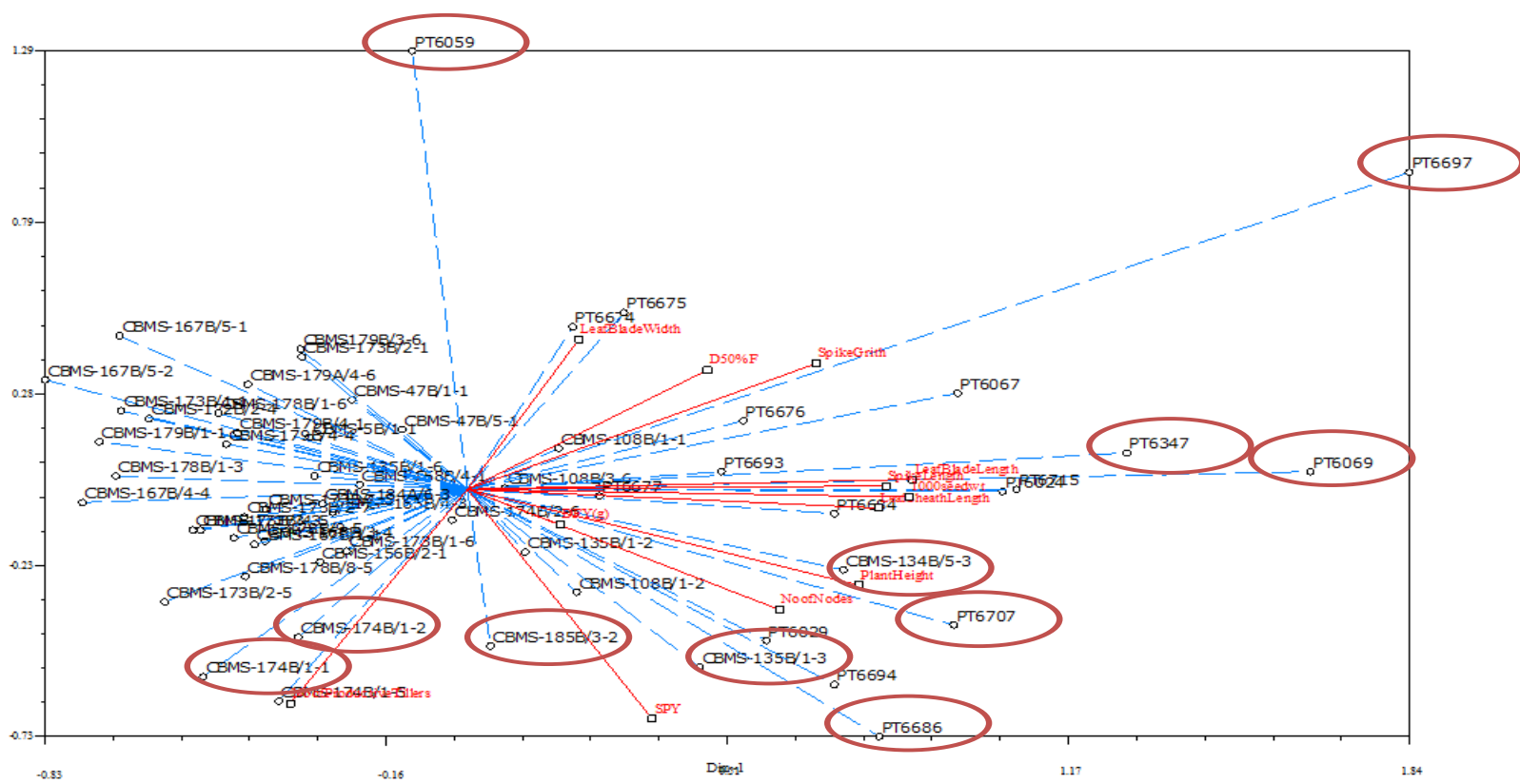

Note: Marked lines showing diverse nature 
The more diverse parents selection are more chance of getting high heterotic effect in hybridization programme and obtaining increased amount of variation in segregating generation Govindaraj et al., (2011).

$\mathrm{D}^{2}$ measures the degree of diversification and determines the relative proportion of each component characters to the total divergence. Based on $\mathrm{D}^{2}$ value existing of genetic diversity, the experimental material were grouped (Table 2) into five major cluster (Fig. 1). These five major clusters further divided into sub clusters. Among the five major clusters, Cluster I was the largest having 40 lines followed by cluster II having 16 lines and remaining clusters III, IV and $\mathrm{V}$ had only one cluster. This indicated that many of the lines having common origin which envisaged that of the lines falling into single cluster. This was supported by Athoni et al., (2016) Singh et al, (2017) and Govindaraj et al., (2011)

The average inter and intra cluster distance were presented in table 3 . The highest intra cluster distance was observed in cluster II and lowest intra cluster distance was recorded in cluster III, IV and $\mathrm{V}$ and showed that this clusters were relatively less divergent and selection belonging to this cluster will give less vigorous progenies in $F_{1}$. Such intra cluster genetic diversity among the parental lines within the same group could be due to heterogeneity, pedigree and degree of general combining ability. Similar finding was reported by Ramya et al., (2017) and Singh et al., (2017). The maximum inter cluster distance was observed in cluster I and V followed by cluster III and IV. Hence selection of lines belonging to this cluster was exhibited high amount of genetic diversity. It may be utilized for parents in hybridization programme. Similar findings were reported by Ramya et al., (2017).

The cluster mean of genetic material were presented in table 4. The line belonging to cluster $\mathrm{V}$ recorded high mean performance for yield attributing quantitative characters like spike length (30.47), spike girth (12.72), leaf blade length (67.65), leaf blade width (5.05), 1000 seed weight (15.30) and dry fodder yield (530.0) and Cluster IV showed the highest value for number of productive tillers/plant (7.0) and plant height (174.10) and days to 50 percent flowering (43.00). Selection of parents from this cluster will serve as a potential breeding material for improving the yield attributing characters in hybridization programme. Similar results were reported by Singh et al., (2017) and Kumari et al., (2016). Early flowering genotypes mostly suitable for cultivation in drought prone area Sankar et al., (2014). Considering this point, individuals belonging to cluster IV used for developing early flowering lines.

In addition to divergence, percent contribution of quantitative characters towards genetic diversity was presented in Table 4. The characters contributing to most of the divergence should be given more importance for the purpose of effective selection and the choice of parents for hybridization. Among the eleven quantitative characters, plant height $(49.74 \%)$ had highest contribution towards total divergence followed by 1000 seed weight (20.45\%) and spike girth (13.85\%). This result was supported by Priya et al., (2010) and Shanmuganathan et al., (2006).

\section{PCA analysis}

PCA is one of the important analyses by simplification of data. PCA analyses are reducing the dimension of the dataset without losing much information of the original data. It provides balanced weight age to the characters which lead to effective contribution towards total diversity on the bass of respective variance. According to Mohammadi and Prasanna (2003) the total variance were breakdown and formed into different principal components. Among the different PC the first PC will explain most of the variability present in the original data. The PCA based on correlation was used to study interrelationship between different characters. 
A scree plot is a simple line segment plot that shows the fraction of total variance present in the genetic material and it is plot the eigen value of correlation matrix in descending order of magnitude. Jain et al., (2016) suggested that the eigen value more than 1 are considered significant and meaningful. In the present study, the first three PC shows eigen value more than 1 correspond to the whole percentage of variance in the material (Table 6).

The cumulative diversity of first three $\mathrm{PC}$ is $63.81 \%$ of the total variation. Hence PC1 has eigen value 4.759 and accounted for $39.66 \%$ of variation. The highest values in the quantitative characters viz., 1000 grain weight (0.39), leaf blade length (0.39), leaf sheath length (0.36), spike length (0.37), spike girth (0.31) and plant height (0.35) indicated that were important contributing characters for variation among the lines. The second and third PC explained 1.551 and 1.275 eigen values and contributing variations $12.93 \%$ and $10.62 \%$ respectively (Table 5).

The PCA 2 related to days to 50 percent flowering (0.27), leaf blade length (0.02), spike length (0.02) and spike girth (0.28). The third PCA composed of leaf blade width (0.54), number of productive tillers/plant $(0.25)$ and single plant yield $(0.25)$. The occurrence of positive and negative loading in PC's indicated that the presence of positive and negative correlation trends between variables in components. Hence the characters which show high positive or negative contributed more to the diversity. Similar findings reported by Singh et al., (2016).

The prominent characters identified in a particular principal component as prime contributors to total variability have the tendency to hang together and can be used effectively for selection in crop breeding programmes. In all three PC's, days to 50 percent flowering, leaf blade width and spike girth showed positive vector loading. These three characters were used as good selection indices for improving the yield in pearl millet.
Similar findings were reported by Ramya et al, (2017), Verma et al., (2015) and Kumari et al., (2014).

The scatter plot for parental line in pearl millet revealed that the lines, PT 6697, PT 6059, PT 6347, PT 6069, CBMS 185B/3-2, CBMS 134B/5-3, CBMS 135B/1-3, CBMS 173B/4-5 and CBMS 174A/1-2. were placed in different quadrants at extreme ends of the plot (Fig. 2). This suggests that these genotypes highly varied from the rest and they are diverse from each other for all the characters. Overall, the PCA analysis under this study shows that phenotypic markers are useful in genotypes of pearl millet and able to identify few key traits that accounted for the largest variability.

The diverse lines in scatter plot also shows diverse in $\mathrm{D}^{2}$ statistical analysis Table 2 . It revealed that utilization of this parental lines for hybridization programme will yield positive results. In addition, it is essential to have knowledge on the general combing ability of the selected parents in the hybridization programme. Therefore, the parents and hybrids generated should be evaluated over different locations or seasons to launch successful hybridization programme and also to test the correlation between genetic distance and hybrid performance for grain yield in Pearl millet.

\section{References}

Athoni, B., I. Boodi, S. Pattanashetti, and A. Guggari. 2016. Genetic diversity for yield and its component traits in pearlmillet [Pennisetum glaucum (L.) R. Br.]. International Journal of Science and Nature7 (4):795-798.

Birchler, J.A., H.Yao, S. Chudalayandi, D.Vaiman and R.A. Veitia. 2010. Heterosis. Plant Cell, 22: 2205- 2112.

Govindaraj, M., B. Selvi, and I. Sudhir Kumar. 2011. Genetic diversity studies in indigenous pearl millet [Pennisetum glauccum (L.) R. Br.] accessions based on biometrical and nutritional quality traits. Indian Journal of Plant Genetic 
Resources 24 (2):186.

Jain, S.K., and P.R. Patel 2016 Principal Component and Cluster Analysis in Sorghum (Sorghum bicolor (L.) Moench) Foreage Research, 42 (2): 90 - 95

Kaushik, J., D. Vart, M. Kumar, A. Kumar, and R. Kumar. 2018. Phenotypic diversity in Pearl Millet [Pennisetum glaucum (L.) R. $\mathrm{Br}$.] germplasm lines. International Journal of Chemical Studies6 (5):11691173.

Kumari, J., M. Bag, S. Pandey, S. Jha, S. Chauhan, G. K. Jha, N. Gautam, and M. Dutta. 2016. Assessment of phenotypic diversity in pearl millet [Pennisetum glaucum (L.) R. Br.] germplasm of Indian origin and identification of trait-specific germplasm. Journal of Crop Pasture Science67 (12):1223-1234.

Mahalanobis, P. C. 1936: On the generalised distance in statistics. J. Genet., 41: 159193

Mohammadi, S., and B. Prasanna. 2003. Analysis of genetic diversity in crop plants-salient statistical tools and considerations. Crop science43 (4):12351248.

Priya, K. V., R. Kumari, R. Suguna, and K. Usharani. 2010. Studies on genetic distance between the diverse germplasm in pearl millet for fodder characters (Pennisetum glaucum (L.) R. Br.). Electronic Journal of Plant Breeding1 (4):1035-1041.

Ramya, A. R., M. L. Ahamed, and R. K. Srivastava. 2017. Genetic diversity analysis among inbred lines of pearl millet [Pennisetum glaucum (L.) R. Br.] based on grain yield and yield component characters. International Journal of
Current Microbiology and Applied Sciences, 6(6): 2240-2250.

Rao, C. R. 1952. Advanced statistical methods in biometric research: A Division Of Macmillan Publishing Co, Inc New York; Collier-Macmillan

Sankar, S. M., C. T. Satyavathi, S. Singh, M. P. Singh, C. Bharadwaj, and S. Barthakur. 2014. Genetic diversity analysis for high temperature stress tolerance in pearl millet [Pennisetum glaucum (L.) R. Br]. Indian Journal of Plant Physiology19 (4):324329.

Sathya, M., N. Vinodhna, and P. Sumathi. 2013. Hierarchical clustering of pearl millet (Pennisetum glaucum (L.) R. Br.) Inbreeds for morpho-physiological traits. International Journal of Current Microbiology and Applied Sciences2 (12):647-652.

Shanmuganathan, M., A. Gopalan, and K. Mohanraj. 2006. Genetic variability and multivariate analysis in pearl millet (Pennisetum glaucum (L.) R. Br.) germplasm for dual purpose. Journal of Agricultural Sciences-Sri Lanka2 (1).

Singh, O M., R.Gowthami, Neelam Shekhawat and Kartar Singh. 2017 Genetic Divergence Studies in Pearl Millet [Pennisetum glacum (L.).R.Br] Germplasm using Mehalanobis D2 Analysis Over Five Years in Hot Arid Climate of Rajastan. International jornal of Current Microbilogy and Applied Science $7: 2319-7706$.

Verma, U., R. Kumar, and M. Dalal. 2015a. Genetic diversity analysis in pearl millet germplasm. International Journal of Agricultural Statistics and Science. 11 (2):335-3.

\section{How to cite this article:}

Rasitha, R., K. Iyanar, R. Ravikesavan and Senthil, N. 2020. Assessment of Genetic Diversity in Parental Lines of Pearl Millet [Pennisetum glaucum (L). R. Br] for Yield and Yield Related Traits. Int.J.Curr.Microbiol.App.Sci. 9(12): 1575-1582.

doi: https://doi.org/10.20546/ijcmas.2020.912.186 